\title{
Experimental Conversion of Colony Social Organization in Fire Ants (Solenopsis invicta): Worker Genotype Manipulation in the Absence of Queen Effects
}

\author{
Dietrich Gotzek • Kenneth G. Ross
}

Revised: 19 September 2007 / Accepted: 23 April 2008 /

Published online: 28 May 2008

(C) Springer Science + Business Media, LLC 2008

\begin{abstract}
Colony social organization in the fire ant Solenopsis invicta appears to be under strong genetic control. In the invasive USA range, polygyny (multiple queens per colony) is marked by the presence of the $G p-9^{b}$ allele in most of a colony's workers, whereas monogyny (single queen per colony) is associated with the exclusive occurrence of the $G p-9^{B}$ allele. Ross and Keller, Behav Ecol Sociobiol 51:287-295 (2002) experimentally manipulated social organization by cross-fostering queens into colonies of the alternate form, thereby changing adult worker $G p-9$ genotype frequencies over time. Although these authors showed that social behavior switched predictably when the frequency of $b$-bearing adult workers crossed a threshold of 5$10 \%$, the possibility that queen effects caused the conversions could not be excluded entirely. We addressed this problem by fostering polygyne brood into queenright monogyne colonies. All such treatment colonies switched social organization to become polygyne, coincident with their proportions of $b$-bearing workers exceeding $12 \%$. Our results support the conclusion that polygyny in S. invicta is induced by a minimum frequency of colony workers carrying the $b$ allele, and further confirm that its expression is independent of queen genotype or history, worker genotypes at genes not linked to $G p-9$, and colony genetic diversity.
\end{abstract}

Keywords Fire ants $\cdot G p-9 \cdot \operatorname{monogyny} \cdot$ polygyny $\cdot$ social organization *

Solenopsis invicta

\section{Introduction}

A fundamental question in biology is how simple units are organized and integrated to ultimately emerge as a complex and unified whole. Such transitions have proved

\footnotetext{
D. Gotzek $(\bowtie)$

Department of Ecology and Evolution, University of Lausanne, 1015 Lausanne, Switzerland e-mail: Dietrich.Gotzek@unil.ch
}

K. G. Ross

Department of Entomology, University of Georgia, Athens, GA 30602, USA 
to be defining moments in the history of life (Maynard Smith and Szathmáry 1995). One such major transition has been the evolution of complex insect societies. Students of social insects recognize that the issue of how emergent colony-level phenotypes evolve and are expressed requires sufficiently complex behavioral models that capture salient features of the underlying genetic architecture. Important components of such models are the number of genes involved in regulating particular social traits, the relative impact of these genes, their interactions with one another (epistasis), their environmentally dependent phenotypic effects (reaction norm), and their contribution to the expression of relevant social phenotypes in other individuals (indirect genetic effects; Robinson 1999; Linksvayer and Wade 2005; Gardner et al. 2007).

Many studies have documented genetic contributions to individual traits of social relevance, including behaviors, in social insects (reviewed in Ross and Keller 2002; Robinson et al. 2005). Fewer have documented genetic effects on colony-level traits such as social organization (Moritz 1988; Hunt et al. 1995, 1998; Cahan et al. 1998; Plateaux-Quénu et al. 2000; Johnson et al. 2002; Julian et al. 2002; Helms Cahan and Keller 2003; Helms Cahan et al. 2004). Of these, the best characterized system involves a single gene of major effect thought to regulate colony queen number in fire ants (Gotzek and Ross 2007). The system has been most clearly elucidated in Solenopsis invicta, the red imported fire ant, in which it also was first described. Some colonies in this and related species are headed by a single reproductive queen (monogyny), whereas others have multiple reproductive queens (polygyny). In the invasive range of $S$. invicta in the USA, an allele dimorphism at the nuclear proteincoding gene $\mathrm{Gp}-9$ (general protein-9) is associated with this social dimorphism (Ross 1997; Ross and Keller 1998, 2002). Female ants of the monogyne form invariably are homozygous for the $B$ allele of $G p-9$. This is in contrast to the polygyne form, in which most females (and, indeed, all egg-laying queens) bear the alternate, $b$ allele; those polygyne workers not bearing the $b$ allele are homozygotes for the $B$ allele, which segregates along with allele $b$ in this form.

Because the $b$ allele is only and always present in polygyne colonies, it is believed to be an indispensable component in the expression of this form of social organization in S. invicta. Significantly, variation at no other nuclear genes has been found to be associated with polygyny (Ross et al. 1997, 1999; Keller and Ross 1999; Shoemaker et al. 2006). While it is conceivable that $G p-9$ simply marks a tightly linked gene or genes that actually determine social organization, a major role for non-genetic factors such as prior worker social experience, queen fecundity, and the social origin of queens in the expression of this colony-level trait has been discounted (Ross and Keller 1998). Based on these results, and the fact that it is the adult workers in fire ant societies who accept or reject supernumerary queens (Fletcher and Blum 1983; Keller and Ross 1993, 1998; Ross and Keller 2002), it has been hypothesized that the presence of the $b$ allele at some minimal frequency in the worker caste induces the polygyne colony phenotype (Ross and Keller 2002). These latter authors conducted an experiment to test this hypothesis by cross-fostering queens between colonies of the different social forms. As predicted, colonies converted to the alternate social form over time as the original workers were replaced by the offspring of the new queens and frequencies of adult $b$-carrying workers steadily increased or decreased. Surprisingly, these social transitions 
consistently occurred at a relatively low threshold frequency of such workers (5$10 \%$ ), which the authors interpreted as evidence that only a low proportion of $b$ bearing workers is required to elicit polygyne behavior by a colony.

Several potential shortcomings in the experimental design of Ross and Keller (2002) are remedied in the present study in order to test the robustness of these previous results. First, the earlier study did not control for possible queen effects, such as worker habituation to queens that might have induced the worker force as a whole to adopt the social behavior characteristic of the fostered queens' colony of origin. Ross and Keller (2002) concluded that such effects were unlikely, given that social conversion did not occur until 70-130 days following queen adoption and because no such queen effects had been detected in a previous set of similar experiments (Ross and Keller 1998). Nonetheless, more subtle queen effects may have influenced the time course of social conversion to give unrealistic estimates of the threshold frequencies of $b$-bearing workers in the Ross and Keller (2002) study. Thus, we avoided potential involvement of queen effects altogether in the present study by fostering brood rather than queens between colonies. Also, the earlier study yielded only relatively coarse estimates of the threshold frequencies of $b$-bearing workers required for social transition. Those estimates are improved upon here by assaying social organization more frequently and by estimating frequencies of $b$ bearing workers from larger samples using a PCR-based rather than a proteinelectrophoretic method. The former method is expected to be less biased because workers of all sizes can be scored (see Goodisman et al. 1999) for discussion of possible biases introduced by electrophoretic scoring of $G p-9$ in workers). Our new results confirm the hypothesis that polygyny in $S$. invicta is induced by the presence in a colony of workers bearing the $b$ allele at even relatively low frequencies and refute a role for effects of queen genotype or history in experimental colony social conversion.

\section{Materials and Methods}

Collection and Rearing of Colonies Twenty queen-right monogyne colonies of $S$. invicta were collected in Oglethorpe and Clarke Counties, Georgia to serve as treatment and control colonies. Fifteen polygyne $S$. invicta colonies were collected from Clarke County to serve as donors of brood and test queens for the experiment. Social organization of the monogyne colonies was confirmed by genotyping 50 workers per colony at $G p-9$ using horizontal starch gel electrophoresis (DeHeer et al. 1999); all 1,000 workers so genotyped were determined to be $B B$ homozygotes. Social organization of the polygyne colonies was confirmed by virtue of their possession of multiple reproductive (wingless, egg-laying) queens, large samples of which were subsequently confirmed to consist only of $B b$ heterozygotes at $G p-9$ (see below). All colonies were returned to the laboratory following collection, separated from the soil, and reared under standard laboratory conditions (Jouvenaz et al. 1977; Ross 1988; Ross and Keller 2002). Sexual brood and winged adults were removed by sieving the colonies during initial establishment in the laboratory and periodically thereafter as brood became sexualized. Colonies and queenless test fragments were fed daily by alternating a high-protein diet (tuna/dog food/peanut butter mix) with a 
high-carbohydrate diet (assorted vegetables/granulated sugar mix). These diets were supplemented with frozen crickets and/or meal worms provided on a daily basis.

Addition of Brood Fifteen monogyne colonies were randomly assigned to the treatment group, while the remaining five colonies were assigned to the control group. We took advantage of the fire ant habit of accepting alien conspecific brood (Stamps and Vinson 1991; Tschinkel 1992) to introduce such brood into the 20 queenright colonies. Treatment group colonies received only polygyne brood, whereas control colonies received only monogyne brood. Brood was introduced twice into each colony, at the start of the experiment and 2 weeks later. On each occasion, each recipient colony received a mixture of brood from several (5-11) donor colonies of the relevant social form. Mixing of fostered brood was done for two reasons. First, it decreased genetic differentiation among the brood cohorts fostered into each colony both within the treatment and control groups and across the two groups; thus, the genetic background of the introduced brood was largely homogenized between the treatment and control colonies at all genes except those linked to Gp-9. Second, brood was mixed in order to match the genetic diversity in the monogyne brood introduced into the control colonies with the high genetic diversity in brood from even a single polygyne donor colony (e.g., Ross and Fletcher 1985). Brood collected from donor colonies was sieved repeatedly prior to mixing to exclude all sexual brood and as many adult workers as possible. The sieved brood of each recipient colony was weighed, and mixed donor brood weighing $50-100 \%$ of the original weight was then added. This typically amounted to $10-25 \mathrm{~g}$ of added brood, which corresponds roughly to 10,000-30,000 individuals (see Porter and Tschinkel 1985).

Successful acceptance by the recipient colonies of adult workers derived from the introduced foreign brood was monitored in the following ways. For the five control colonies and five randomly chosen treatment colonies, genotypic profiles at the allozyme loci Est-4, G3pdh-1, and Pgm-1 (Ross 1993) were generated by electrophoretically genotyping ten adult workers per colony before brood addition; because monogyne colonies constitute simple families (Ross and Fletcher 1985), the limited range of variation occurring within each at these loci was uncovered with this protocol. Three weeks after final brood addition, at the time of the second bioassay, another 20 adult workers from each of these colonies were genotyped at the same loci. The proportions of these individuals with multilocus genotypes inconsistent with the original colony profile are minimum estimates of the proportion of foreign workers in the colony at that time (foreign workers whose genotypes match those in the original colony are indistinguishable from the resident queen's offspring). The genetic relatedness of colony-mates sampled before and after brood addition was estimated from the allozyme data as a measure of colony genetic diversity using the program RELATEDNESS 5.0 (Queller and Goodnight 1989).

For all 15 treatment colonies, acceptance of the foreign brood and emerged adults was further confirmed by estimating the frequencies of adult workers bearing the $b$ allele at $G p-93$ weeks after the second (final) brood addition. Again, this provides a minimum estimate of the proportion of foreign workers in the colony (about a third of the introduced polygyne brood, on average, are expected to bear the same $B B$ genotype possessed by the original workers in the monogyne treatment colonies; e.g., Ross and Keller 2002; Fritz et al. 2006). 
Bioassay of Social Organization and Estimation of Frequencies of b-Bearing Workers Bioassays followed the general protocol of Ross and Keller (2002). For each, a large test colony fragment containing brood but no queen was prepared and held in isolation from the parent colony for $48 \mathrm{~h}$; fragments were held queenless for this period because queenright monogyne colonies will not accept any foreign queen (s) (Fletcher 1986; Vander Meer and Alonso 2002). Next, four polygyne reproductive queens were introduced into the foraging arena of the queenless fragment. All surviving queens and any identifiable heads or thoraces of executed queens were removed $24 \mathrm{~h}$ after the queen introductions. These were genotyped electrophoretically to confirm that all introduced queens possessed the $b$ allele of $G p-9$. Survival of multiple introduced polygyne ( $b$-carrying) queens for $24 \mathrm{~h}$ indicates expression of the polygyne colony phenotype, whereas execution of all such queens signals expression of the monogyne phenotype (Ross and Keller 1998, 2002). Queenless fragments were recombined with their parent colony immediately after completion of each assay.

The first bioassay was conducted just before initial brood addition to confirm that the monogyne test colonies behaved as expected. The second assay was conducted 3 weeks after the final addition of foreign brood. This approximates the developmental period from newly laid egg to eclosion of the adult minor worker in S. invicta under our rearing conditions (O'Neal and Markin 1975), so that most of the introduced brood probably had developed to mature (several day old) adult workers by the time of the second assay. Colonies subsequently were bioassayed at approximately 2 -week intervals. Treatment colonies were terminated when they displayed a reversal to monogyne social behavior that was stable for at least three consecutive assays or, in the absence of such reversal, eight months after the final brood addition. Most adult workers probably live no more than four months under our rearing conditions (Calabi and Porter 1989), so few workers derived from foreign brood were expected to inhabit the latter colonies by the end of the experiment.

Estimation of the frequency of adult workers bearing the $b$ allele was done at the time of the first two bioassays for each treatment colony. The procedure was suspended after a colony converted to polygyny, but was re-instituted once it reverted back to monogyny (or, in the few cases in which such reversals did not occur, at the last assay). For each estimation, nests were disturbed by lifting their tops and a random sample of several hundred workers from the nests and foraging arena was collected. The DNA of 75 of the collected individuals was extracted using a simple method (Turelli and Hoffmann 1995) and used as the template in $b$ allelespecific PCR reactions (Mescher et al. 2003). The microsatellite locus Sol-42 (Krieger and Keller 1997) was multiplexed in the PCRs as a control for successful amplification. Amplification products were run out in $1.5 \%$ agarose gels stained with ethidium bromide and were visualized under UV illumination. Presence of the $b$ allele was indicated by amplification of a 219-bp fragment (Mescher et al. 2003). Any ambiguous amplifications (i.e., those in which the microsatellite locus did not amplify) were redone; after a second failure the sample specimen was substituted by another. A jackknife resampling procedure was used to estimate the frequency of $b$ bearing workers from each sample, with the $95 \%$ confidence intervals obtained by assuming the $t$-distribution (Weir 1996). For samples following brood addition in 
which only $B B$ workers were collected, $95 \%$ confidence intervals were obtained after assuming that the next individual assayed (the 76th) would have possessed allele $b$.

\section{Results}

Acceptance of Foreign Brood and Emerged Adult Workers Foreign brood was readily accepted and reared to adulthood by all treatment and control colonies. A minimum of $10-45 \%$ of the adult workers in each control colony and $5-10 \%$ of the workers in five randomly chosen treatment colonies are estimated to have been derived from foreign brood (monogyne and polygyne, respectively) 3 weeks after final brood addition, based on their possession of multilocus allozyme genotypes inconsistent with the original colony profiles. Based on presence of the $b$ allele of $G p-9$, a minimum of $12-42 \%$ of adult workers in each treatment colony are estimated to have been derived from foreign polygyne brood at this juncture. Average colony-mate relatedness estimated from three allozyme loci fell from 0.69 (95\% jackknife confidence interval 0.59-0.78) before brood addition to $0.38(0.22-$ $0.55)$ in the treatment colonies and $0.29(0.18-0.39)$ in the control colonies at the 3 -week juncture, suggesting comparable within-colony genetic diversity in the two classes of colonies at the time of the second bioassay.

Conversion of Colony Social Organization All colonies rejected all polygyne (bcarrying) queens introduced in the first bioassay, conducted immediately prior to the addition of foreign brood, and thus displayed the social behavior expected of monogyne colonies. The outcome of the second assay, conducted 3 weeks after final brood addition, was markedly different. All treatment colonies accepted all four introduced queens, thus invariably displaying polygyne social behavior. Associated with this change in social organization, frequencies of adult workers bearing the $b$ allele in each colony rose from $0 \%$ to no less than $12 \%$ by the time of this second assay (Fig. 1). In complete contrast to the treatment colonies, none of the control colonies accepted any introduced queens in the second assay or any of the subsequent 18 assays conducted on each during the course of the experiment. Thus, the controls behaved as typical monogyne colonies throughout the course of the experiment.

Fig. 1 Social behavior expressed by treatment colonies during bioassays (identification codes for each colony shown to the right of each panel), and proportions of $B B$ and $b$-bearing workers at conversions in social organization (thin bars represent 95\% jackknife confidence intervals). The first assay was conducted prior to addition of foreign brood, when all colonies contained only $B B$ workers. The second assay was conducted approximately 3 weeks after the final addition of foreign brood. All subsequent assays were conducted approximately every 2 weeks. Worker $G p-9$ frequencies were determined only at the first two assays and at the subsequent assay at which a colony reverted in social behavior (or at the end of the experiment, see text). The type of social behavior expressed is indicated also for each assay at which $G p-9$ frequencies were not determined, with the " $X$ " indicating the number of consecutive assays yielding the identical form of behavior. $M$ : monogyne behavior expressed (no supernumerary queens accepted), $P$ : polygyne behavior expressed (multiple supernumerary queens accepted), question mark: ambiguous social behavior expressed (single queen accepted) by colony M-15 (see text). Colony M-04 declined after the second assay, at which point it was dropped from the experiment. 


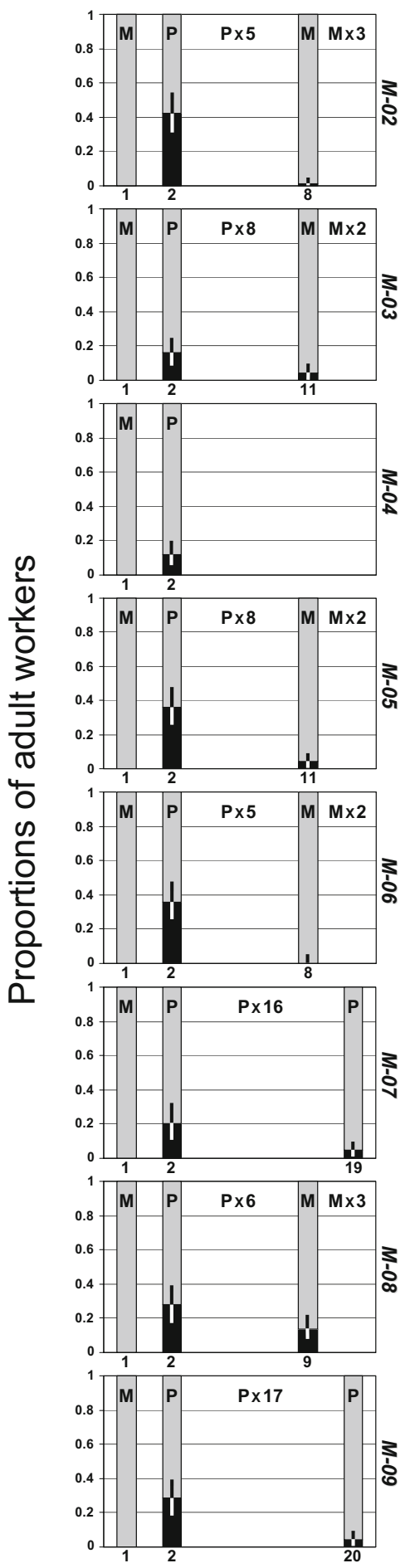

Bioassay number

\section{$\square$ BB workers \\ b-bearing workers}
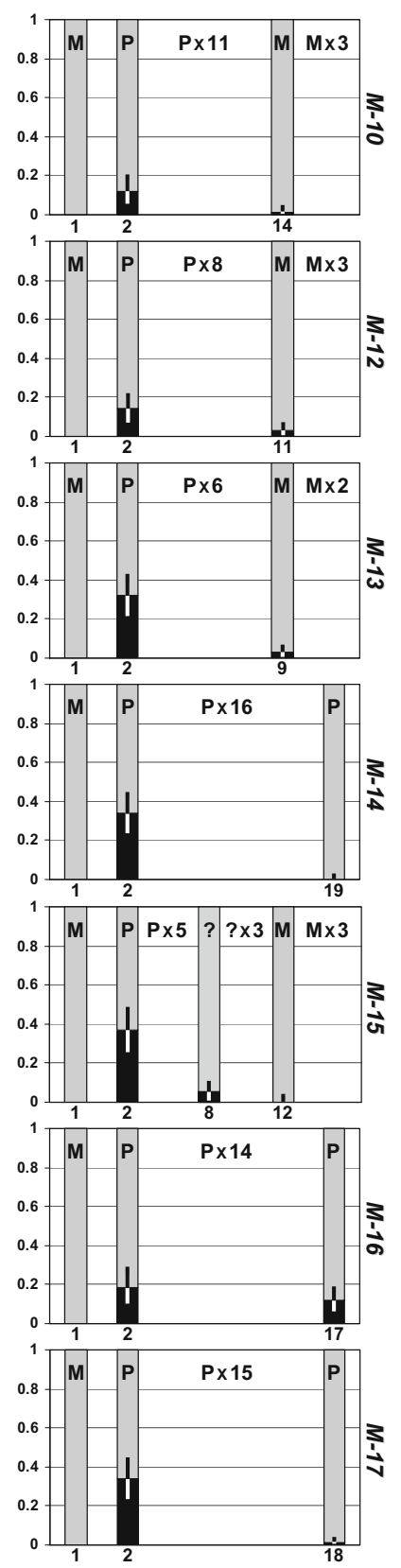

Bioassay number 
One of the 15 treatment colonies (M-04) was excluded from further analysis because it declined dramatically in size after the second assay and the queen eventually died. Of the remaining 14 colonies, nine reverted back to monogyne behavior by the end of the study period (see Fig. 1), an event that occurred between 12 and 24 weeks after the second assay as frequencies of $b$-bearing workers inevitably declined. One of these nine colonies (M-15) transiently displayed ambiguous social behavior during this period of reversal; after 10 weeks of polygyne behavior, it accepted only a single $B b$ queen in four consecutive assays (for 8 weeks) before finally rejecting all introduced queens and thus displaying genuine monogyne behavior for the ensuing four assays.

The proportion of $b$-carrying individuals in the 15 treatment colonies at the time that they first displayed polygyne behavior (second bioassay) ranged from $12 \%$ to $42 \%$ (Fig. 1). Among the nine colonies that reverted back to monogyny, this proportion dropped to between $0 \%$ and $14.7 \%($ mean $=3.4 \%)$ at the sample point when reversal was first detected. Five treatment colonies never reverted back to monogyne behavior over the course of the experiment. Four of these still had detectable levels of $b$-carrying workers at the end of the experiment (estimated at 1$11.8 \%$ ), but we were unable to recover any such workers in colony M-14 (even in an expanded sample of 100 individuals). The proportion of $b$-bearing workers in the five permanently polygyne treatment colonies averaged $4.5 \%$ at the end of the experiment.

In Fig. 2, each estimate of the proportion of $b$-bearing workers in the treatment colonies is grouped according to the type of social behavior displayed by the colony at the time the sample was taken. The distributions are quite discrete for the two forms of behavior, with an apparent discontinuity occurring at around 5-10\% $b$ carrying workers. Conspicuous exceptions are the single monogyne-behaving colony with a frequency close to $15 \%$ and the two polygyne-behaving colonies with frequencies below 4\%. These results generally correspond with the finding of Ross and Keller (2002) that colonies with cross-fostered queens underwent social

Fig. 2 Proportions of adult $b$-bearing workers in treatment colonies expressing monogyne or polygyne social behavior. The threshold proportion of $b$-bearing workers hypothesized by Ross and Keller (2002) to be required for conversion between monogyny and polygyny is highlighted with stippling.

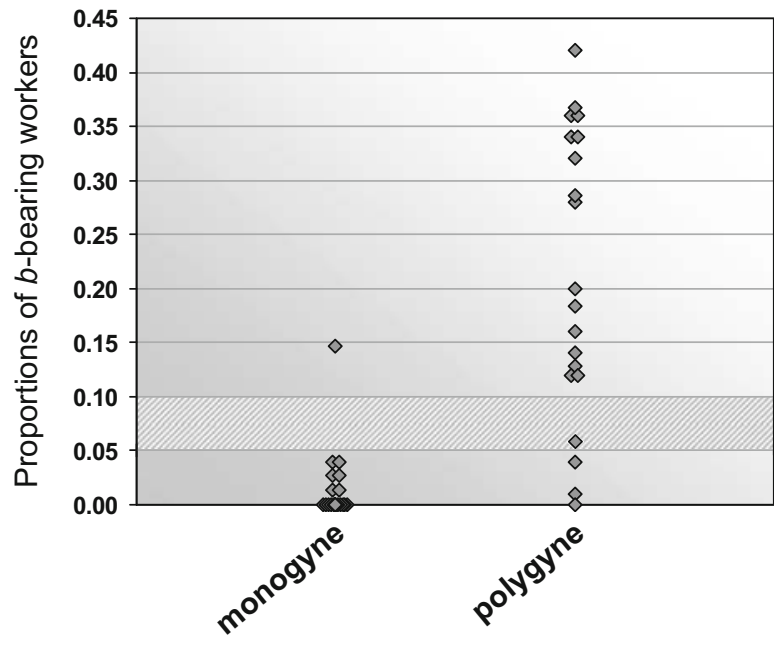

Colony social organization 
transitions when their frequencies of $b$-carrying workers crossed a threshold of $5-10 \%$.

\section{Discussion}

The results of this study support the hypothesis that colony social organization in $S$. invicta is determined by the presence or absence of adult workers bearing the $b$ allele at the gene $G p-9$. Specifically, polygyny is expressed when such workers are present in a colony at a minimal frequency of several percent, whereas monogyny typically is expressed when such workers make up fewer than several percent of the worker force or are absent altogether. To test this hypothesis, we introduced brood pooled from natural polygyne colonies, which contain a high frequency of $b$-carrying individuals, into monogyne colonies, which lack them. Shortly thereafter, adult workers bearing the allele appeared at moderate frequencies and these treatment colonies concurrently switched social organization from monogyny to polygyny. Control colonies, all of which failed to undergo such social conversion, received a mixture of brood from monogyne colonies. This protocol served to homogenize brood from the different donor types with respect to their levels of genetic diversity as well as their genetic background at genes not linked to $G p-9$. By retaining each colony's original queen, we avoided any potential influence of direct queen effects on expression of social organization in the experiment.

Our results are important for several reasons. First, they strongly suggest that social organization in $S$. invicta is under worker control rather than queen control, and that worker genotype composition at $G p-9$ (or linked genes) is the dominant factor determining collective worker social behavior (as suggested also by the experiments of Ross and Keller 1998). Our results further show that genes not linked to $G p-9$ are not involved in regulation of social organization, a conclusion supported as well by the overall similarity of sympatric populations of the two forms at numerous genetic markers (Ross et al. 1987, 1997, 1999, 2007; Shoemaker et al. 2006). Finally, our demonstration that differences in levels of genetic diversity between colonies of the two forms are irrelevant to the expression of social organization stands in contrast to the view that polygyny may be induced by high genetic diversity and the correspondingly high odor cue diversity it engenders (see Hölldobler and Wilson 1977; Morel et al. 1990; Obin et al. 1993; Ross et al. 1996).

One benefit of our experimental design is that we were able to test the effect of $b$ carrying workers on expression of social organization twice for each colony-once as these workers increased in frequency shortly after brood addition and again later as they dropped in frequency due to their replacement by the resident queen's offspring (all of which possessed genotype $B B$ ). At our first bioassay after brood addition, each treatment colony had switched from monogyne to polygyne social behavior, coincident with the appearance of adult $b$-carrying workers at estimated frequencies of $12 \%$ to $42 \%$. This result is fully consistent with the findings of Ross and Keller (2002) based on a fundamentally different experimental design (fostering queens rather than brood between colonies), where conversion from monogyny to polygyny occurred as the frequency of adult $b$-bearing workers in a colony crossed a threshold of $5-10 \%$. We note that polygyne colonies in the wild invariably have far 
greater frequencies of such workers owing to the fact that all reproductive queens of this social form carry the $b$ allele (Ross 1997; Ross and Keller 1998, 2002; Fritz et al. 2006; Goodisman et al. 2007). Thus, in one elementary sense our combined laboratory experiments provide a robust proximate explanation of why naturally occurring colonies with $b$-carrying queens invariably display the polygyne social phenotype.

The second test of the effect of $b$-bearing workers on expression of social organization, as their frequencies returned to low levels due to worker turnover, also was largely consistent with the findings of Ross and Keller (2002). Nine of the 14 relevant treatment colonies reverted back to monogyny within several months after their initial conversion to polygyny; all nine exhibited frequencies of $b$-bearing workers at or near the $5-10 \%$ threshold at the time of their reversal (colony M-08 had the highest frequency of such workers, $14.7 \%$, with a lower jackknife confidence limit of $8 \%$ ). Among the five colonies that did not revert to monogyny, four still had $b$-bearing workers present at sample frequencies of $1 \%$ to $12 \%$, which could correspond to actual frequencies in the colonies ranging as high as $3 \%$ to $18 \%$ (based on the upper $95 \%$ confidence limits). We found no $b$-carrying workers in a sample of 100 from the fifth such colony (M-14), suggesting that such workers were exceedingly rare or absent altogether in this polygyne-behaving colony. This lone example represents a seeming contradiction to the view that expression of polygyny requires the presence of adult workers bearing the $b$ allele at the gene $G p-9$.

On the other hand, there are potential sources of error or natural variation that may reconcile the case of colony M-14 late in the experiment with the great majority of other test colonies in this study and that of Ross and Keller (2002). Although our increased sample sizes, use of a PCR-based technique to score worker $G p-9$ alleles, and increased frequency of bioassays represent methodological improvements over the previous study, estimation errors attributable to finite sample sizes and the 2-week intervals between each sample may still explain discrepancies in any single anomalous estimate. Perhaps more importantly, variation in any of a number of potential colony attributes (e.g., colony size, adult worker/brood ratio, queen vigor) may in some cases mitigate or even override the effect of worker $G p-9$ genotype composition in determining colony social organization; that is, the penetrance of $G p$ 9 may not be complete under all circumstances in experimental laboratory colonies. As an extreme example, colonies of each form can be induced to accept queens they would normally reject based on the joint queen/worker $G p-9$ genotypes if they are held queenless for extended periods (Fletcher 1986; Ross and Keller 2002; Vander Meer and Alonso 2002). Given the complex, emergent nature of a colony-level phenotype such as social organization, it is remarkable that our combined experimental results are so congruent in pointing to a paramount role of worker $G p-9$ composition in its expression.

One potentially confounding attribute not considered in this study or that of Ross and Keller (2002) is colony size. Under some conceivable proximate models of worker regulation of queen number, the frequency of $b$-bearing workers required to elicit polygyny is not expected to scale linearly with colony population. For instance, if the cues introduced by $b$-bearing workers that induce a switch in colony social phenotype are pheromonal rather than behavioral in nature, these cues may be more persistent or easily disseminated in smaller than larger colonies. If not readily 
degraded, they could persist in the presence of recently deceased $b$-carrying workers at levels effective in small but not large colonies. If colony M-14 and other apparent outliers were unusually small late in the experiment due to stress from continued manipulation and worker attrition, very low frequencies of $b$-bearing workers may still have been sufficient to maintain the prevailing polygyne social phenotype.

This point raises the more general issue of how a small fraction of workers can influence a colony-level phenotype that, at its core, constitutes collective tolerance of multiple reproductive queens bearing the same $G p-9$ allele as these minority workers (e.g., Keller and Ross 1998). Although there are several examples of such behaviorally dominant colony phenotypes in social insects, some of which can be readily explained by the cumulative actions of just a few individuals [e.g., hygienic behavior of honey bees (Trump et al. 1967) and sex ratio manipulation in ants (Aron et al. 1995; Passera et al. 2001)], development of proximate explanations of regulation of queen number in fire ants is hampered by an almost complete lack of knowledge of the individual behaviors involved (but see Keller and Ross 1998). Ross and Keller (2002) proposed two potential classes of mechanisms by which relatively few $b$-bearing workers could influence a large worker force to tolerate multiple $b$-bearing queens. The first is behavioral manipulation, which could occur, for instance, by $b$-bearing workers releasing an appeasement pheromone to forestall aggressive responses toward queens or by $b$-bearing workers transporting queens into the nest and physically protecting them from attack until aggression dissipates. The second is habituation of the entire colony to a unique odor (pheromone) associated with $b$-carrying adults (workers and queens). Of the two, we favor this second alternative for several reasons. First, the likelihood of a small minority of workers finding and somehow protecting a queen seeking acceptance into a colony from other workers seems remote. On the other hand, an odor cue can perhaps more easily explain the dominant behavioral effect of rare individuals in a colony, as discussed above. Finally, $G p-9$ encodes a transport protein belonging to the odorant binding protein (OBP) gene family (Krieger and Ross 2002), so if directly involved in control of queen number it conceivably could exert its effects via a role in odor transport, emanation, or detection (see Vogt 2005 for discussion of the possible roles of OBPs in insect chemoreception).

Ideally, our experimental protocol would have included bioassays of the treatment colonies immediately after initial brood addition in order to completely rule out any role of the brood in inducing social conversion. For instance, maternal effects mediated through surface hydrocarbons placed on eggs by queens could be hypothesized to play such a role (e.g., Endler et al. 2006). However, the experimental results of Ross and Keller (2002) appear to contradict any role for brood (including eggs) in influencing social organization, given the considerable delay between cross-fostering of queens and conversion in colony social phenotype found in that study. Similar long delays between the final addition of polygyne brood and reversion of treatment colonies from polygyny to monogyny in the present study also are inconsistent with the brood playing such a role.

In conclusion, this study confirms a strong genetic component to social organization in $S$. invicta that is mediated by colony worker genotype frequencies at $G p-9$ (or closely linked genes). We have shown that polygyne social behavior is induced by the presence of $b$-carrying adult workers, even at quite low frequencies, 
whereas monogyne behavior is expressed in the absence of such workers. Direct queen effects were eliminated as possible causative factors in our experimental design, as were effects of genes not linked to $G p-9$ and of overall colony genetic diversity. The processes involved in worker regulation of colony queen number in $S$. invicta, which constitutes the core element of social organization, are presently poorly understood. Detailed understanding of queen acceptance and rejection behaviors, coupled with improved knowledge of the biochemical and physiological roles of Gp-9 (and linked candidate genes), are required to explicitly model the proximate and evolutionary mechanisms underlying the seemingly simple yet evolutionarily important transition from one social form to the other in fire ants.

Acknowledgements We thank Chris DeHeer, Laurent Keller, Emily Matthews, and Yannick Wurm for comments on the manuscript.

\section{References}

Aron S, Vargo EL, Passera L (1995) Primary and secondary sex ratios in monogyne colonies of the fire ant. Anim Behav 49:749-757

Cahan S, Helms KR, Rissing SW (1998) An abrupt transition in colony founding behaviour in the ant Messor pergandei. Anim Behav 55:1583-1594

Calabi P, Porter SD (1989) Worker longevity in the fire ant Solenopsis invicta: ergonomic considerations of correlations between temperature, size and metabolic rates. J Insect Physiol 35:643-649

DeHeer CJ, Goodisman MAD, Ross KG (1999) Queen dispersal strategies in the multiple-queen form of the fire ant Solenopsis invicta. Am Nat 153:660-675

Endler A, Liebig J, Hölldobler B (2006) Queen fertility, egg marking and colony size in the ant Camponotus floridanus. Behav Ecol Sociobiol 59:490-499

Fletcher DJC (1986) Triple action of queen pheromones in the regulation of reproduction in fire ant (Solenopsis invicta) colonies. In: Porchet M, Andries J-C, Dhainaut A (eds) Advances in invertebrate reproduction 4. Elsevier, London, pp 305-316

Fletcher DJC, Blum MS (1983) Regulation of queen number by workers in colonies of social insects. Science 219:312-314

Fritz GN, Vander Meer RK, Preston CA (2006) Selective male mortality in the red imported fire ant, Solenopsis invicta. Genetics 173:207-213

Gardner A, West SA, Barton NH (2007) The relation between multilocus population genetics and social evolution theory. Am Nat 169:207-226

Goodisman MAD, Mack PD, Pearse DE, Ross KG (1999) Effects of a single gene on worker and male body mass in the fire ant Solenopsis invicta (Hymenoptera: Formicidae). Ann Entomol Soc Am 92:563-570

Goodisman MAD, Sankovich KA, Kovacs JL (2007) Genetic and morphological variation over space and time in the invasive fire ant Solenopsis invicta. Biological Invasions 9:571-584

Gotzek D, Ross KG (2007) Genetic regulation of colony social organization in fire ants: an integrative overview. Q Rev Biol 82:201-226

Helms Cahan S, Keller L (2003) Complex hybrid origin of genetic caste determination in harvester ants. Nature 424:306-309

Helms Cahan S, Julian GE, Rissing SW, Schwander T, Parker JD, Keller L (2004) Loss of phenotypic plasticity generates genotype-caste association in harvester ants. Curr Biol 14:2277-2282

Hölldobler B, Wilson EO (1977) The number of queens: an important trait in ant evolution. Naturwissenschaften 64:8-15

Hunt GJ, Page RE, Fondrk MK, Dullum CJ (1995) Major quantitative trait loci affecting honey bee foraging behavior. Genetics 141:1537-1545

Hunt GJ, Guzmán-Novoa E, Fondrk MK, Page RE (1998) Quantitative trait loci for honey bee stinging behavior and body size. Genetics 148:1203-1213

Johnson RN, Oldroyd BP, Barron AB, Crozier RH (2002) Genetic control of the honey bee (Apis mellifera) dance language: segregating dance forms in a backcrossed colony. J Heredity 93:170-173 
Jouvenaz DP, Allen GE, Banks WA, Wojcik DP (1977) A survey for pathogens of fire ants, Solenopsis spp. in the southeastern United States. Fla Entomol 60:275-279

Julian GE, Fewell JH, Gadau J, Johnson RA, Larrabee D (2002) Genetic determination of the queen caste in an ant hybrid zone. Proc Natl Acad Sci U S A 99:8157-8160

Keller L, Ross KG (1993) Phenotypic basis of reproductive success in a social insect: genetic and social determinants. Science 260:1107-1110

Keller L, Ross KG (1998) Selfish genes: a green beard in the red fire ant. Nature 394:573-575

Keller L, Ross KG (1999) Major gene effects on phenotype and fitness: the relative roles of Pgm-3 and $G p-9$ in introduced populations of the fire ant Solenopsis invicta. J Evol Biol 21:672-680

Krieger MJB, Keller L (1997) Polymorphism at dinucleotide microsatellite loci in fire ant Solenopsis invicta populations. Mol Ecol 6:997-999

Krieger MJB, Ross KG (2002) Identification of a major gene regulating complex social behavior. Science 295:328-332

Linksvayer TA, Wade MJ (2005) The evolutionary origin and elaboration of sociality in the aculeate Hymenoptera: maternal effects, sib-social effects, and heterochrony. Q Rev Biol 8:317-336

Maynard Smith J, Szathmáry E (1995) The major transitions in evolution. Freeman, New York

Mescher MC, Ross KG, Shoemaker DD, Keller L, Krieger MJB (2003) Distribution of the two social forms of the fire ant Solenopsis invicta (Hymenoptera: Formicidae) in the native South American range. Ann Entomol Soc Am 96:810-817

Morel L, Vander Meer RK, Lofgren CS (1990) Comparison of nestmate recognition between monogyne and polygyne populations of Solenopsis invicta (Hymenoptera: Formicidae). Ann Entomol Soc Am 83:642-647

Moritz RFA (1988) A reevaluation of the two-locus model for hygienic behavior in honeybees (Apis mellifera L.). J Heredity 79:257-262

Obin MS, Morel L, Vander Meer RK (1993) Unexpected, well-developed nestmate recognition in laboratory colonies of polygyne imported fire ants (Hymenoptera: Formicidae). J Insect Behav 6:579-589

O'Neal J, Markin GP (1975) Brood development of the various castes of the imported fire ant, Solenopsis invicta Buren (Hymenoptera: Formicidae). J Kans Entomol Soc 48:152-159

Passera L, Aron S, Vargo EL, Keller L (2001) Queen control of sex ratio in fire ants. Science 293:13081310

Plateaux-Quénu C, Plateaux L, Packer L (2000) Population-typical behaviours are retained when eusocial and non-eusocial forms of Evylaeus albipes (F.) (Hymenoptera, Halictidae) are reared simultaneously in the laboratory. Insectes Soc 47:263-270

Porter SD, Tschinkel WR (1985) Fire ant polymorphism (Hymenoptera: Formicidae): factors affecting worker size. Ann Entomol Soc Am 78:381-386

Queller DC, Goodnight KF (1989) Estimating relatedness using genetic markers. Evolution 43:258-275

Robinson GE (1999) Integrative animal behaviour and sociogenomics. Trends Ecol Evol 14:202-205

Robinson GE, Grozinger CM, Whitfield CW (2005) Sociogenomics: social life in molecular terms. Nat Rev Gen 6:257-270

Ross KG (1988) Differential reproduction in multiple-queen colonies of the fire ant Solenopsis invicta (Hymenoptera: Formicidae). Behav Ecol Sociobiol 23:341-355

Ross KG (1993) The breeding system of the fire ant Solenopsis invicta: effects on colony genetic structure. Am Nat 141:554-576

Ross KG (1997) Multilocus evolution in fire ants: effects of selection, gene flow, and recombination. Genetics 145:961-974

Ross KG, Fletcher DJC (1985) Comparative study of genetic and social structure in two forms of the fire ant, Solenopsis invicta (Hymenoptera: Formicidae). Behav Ecol Sociobiol 17:349-356

Ross KG, Keller L (1998) Genetic control of social organization in an ant. Proc Natl Acad Sci U S A 95:14232-14237

Ross KG, Keller L (2002) Experimental conversion of colony social organization by manipulation of worker genotype composition in fire ants (Solenopsis invicta). Behav Ecol Sociobiol 51:287-295

Ross KG, Vargo EL, Fletcher DJC (1987) Comparative biochemical genetics of three fire ant species in North America, with special reference to the two social forms of Solenopsis invicta (Hymenoptera: Formicidae). Evolution 41:979-990

Ross KG, Vargo EL, Keller L (1996) Social evolution in a new environment: the case of introduced fire ants. Proc Natl Acad Sci U S A 93:3021-3025

Ross KG, Krieger MJB, Shoemaker DD, Vargo EL, Keller L (1997) Hierarchical analysis of genetic structure in native fire ant populations: results from three classes of molecular markers. Genetics 147:643-655 
Ross KG, Shoemaker DD, Krieger MJB, DeHeer CJ, Keller L (1999) Assessing genetic structure with multiple classes of molecular markers: a case study involving the introduced fire ant Solenopsis invicta. Mol Biol Evol 16:525-543

Ross KG, Krieger MJB, Keller L, Shoemaker DD (2007) Genetic variation and structure in native populations of the fire ant Solenopsis invicta: evolutionary and demographic implications. Biol J Linn Soc 92:541-560

Shoemaker DD, DeHeer CJ, Krieger MJB, Ross KG (2006) Population genetics of the invasive fire ant Solenopsis invicta (Hymenoptera: Formicidae) in the United States. Ann Entomol Soc Am 99:12131233

Stamps WT, Vinson SB (1991) Raiding in newly founded colonies of Solenopsis invicta Buren (Hymenoptera: Formicidae). Environ Entomol 20:137-141

Trump RF, Thompson VC, Rothenbuhler WC (1967) Behaviour genetics of nest cleaning in honeybees. V. Effect of previous experience and composition of mixed colonies on response to disease-killed brood. J Apic Res 6:127-131

Tschinkel WR (1992) Brood raiding in the fire ant Solenopsis invicta (Hymenoptera: Formicidae): laboratory and field observations. Ann Entomol Soc Am 85:638-646

Turelli M, Hoffmann AA (1995) Cytoplasmic incompatibility in Drosophila simulans: dynamics and parameter estimates from natural populations. Genetics 140:1319-1338

Vander Meer RK, Alonso LE (2002) Queen primer pheromone affects conspecific fire ant (Solenopsis invicta) aggression. Behav Ecol Sociobiol 51:122-130

Vogt RG (2005) Molecular basis of pheromone detection in insects. In: Gilbert LI, Iatro K, Gill S (eds) Comprehensive insect physiology, biochemistry, pharmacology and molecular biology. Endocrinology vol. 3. Elsevier, London, pp 753-804

Weir BS (1996) Genetic data analysis II. Sinauer, Sunderland, Massachusetts 